\title{
Analyses of fear memory in Arc/Arg3.1-deficient mice: intact short-term memory and impaired long-term and remote memory
}

\author{
Kazuyuki Yamada $^{1 *}$, Chihiro Homma ${ }^{1}$, Kentaro Tanemura ${ }^{2}$, Toshio Ikeda ${ }^{3}$, \\ Shigeyoshi Itohara ${ }^{3}$, Yoshiko Nagaoka ${ }^{1}$
}

\footnotetext{
${ }^{1}$ Support Unit for Animal Resources Development, Research Resources Center, Brain Science Institute, RIKEN, Saitama, Japan; ${ }^{2}$ Division of Cellular \& Molecular Toxicology, Biological Safety Research Center, National Institute of Health Sciences, Tokyo, Japan;

${ }^{3}$ Laboratory for Behavioral Genetics, Brain Science Institute, Saitama, Japan.

Email: kaz-yamada@brain.riken.jp
}

Received 25 April 2011; 23 May 2011; 26 May 2011

\begin{abstract}
Activity-regulated cytoskeleton-associated protein (Arc/Arg3.1) was originally identified in patients with seizures. It is densely distributed in the hippocampus and amygdala in particular. Because the expression of Arc/Arg3.1 is regulated by nerve inputs, it is thought to be an immediate early gene. As shown both in vitro and in vivo, Arc/Arg3.1 is involved in synaptic consolidation and regulates some forms of learning and memory in rats and mice $[1,2]$. Furthermore, a recent study suggests that Arc/Arg3.1 may play a significant role in signal transmission via AMPA-type glutamate receptors [3-5]. Therefore, we conducted a detailed analysis of fear memory in Arc/Arg3.1-deficient mice. As previously reported, the knockout animals exhibited impaired fear memory in both contextual and cued test situations. Although Arc/Arg3.1-deficient mice showed almost the same performance as wild-type littermates $4 \mathrm{hr}$ after a conditioning trial, their performance was impaired in the retention test after $24 \mathrm{hr}$ or longer, either with or without reconsolidation. Immunohistochemical analyses showed an abnormal density of GluR1 in the hippocampus of Arc/Arg3.1-deficient mice; however, an application of AMPA potentiator did not improve memory performance in the mutant mice. Memory impairment in Arc/Arg3.1-deficient mice is so robust that the mice provide a useful tool for developing treatments for memory impairment.
\end{abstract}

Keywords: Activity-Regulated Cytoskeleton-Associated Protein (Arc/Arg3.1); Knockout (Ko) Mouse;

Short-Term Memory; Long-Term Memory; Reconsoli- dation; AMPA Receptor

\section{INTRODUCTION}

Activity-regulated cytoskeleton-associated protein (Arcl Arg3.1) is encoded by an effector immediate early gene and is selectively localized in neuronal dendrites [6]. Arc/Arg3.1 and its encoded protein are thought to play a role in activity-dependent plasticity of dendrites [7]. Arc/Arg3.1 mRNA is greatly increased by long-term potentiation (LTP)-inducing electrical stimuli [8,9]; administration of psycho-stimulant drugs such as cocaine [10], amphetamines/methamphetamines [11-13], and phencyclidine [14]; insulin [15], middle cerebral artery occlusion [16], electroconvulsive shock [17,18], olfactory inputs [19], mating [20], stress [21], and other stimuli that prompt neuronal activity $[22,23]$. The mRNA is then rapidly delivered to the dendrites [9]. Furthermore, intense synaptic activity induces selective localization of Arc/Arg3.1 mRNA to activated synapses [9,24]. Therefore, Arc/Arg3.1 is believed to be related to synaptic plasticity, and thus many electrophysiological and biochemical studies have been conducted to investigate this possibility [7-9,25]. These studies have revealed that Arc/Arg3.1 may be a key molecule involved in latephase LTP, during which long-term memories (LTM) are thought to be established.

Guzowski et al. [1] found that rats in which $\mathrm{Arc} /$ Arg3.1 antisense oligonucleotides were infused into the hippocampus perform relatively poorly in a water-maze probe test. This result strongly suggested that Arc/Arg3.1 plays an important role in the formation of some forms of spatial LTM. Furthermore, Plath et al. [2] developed Arc/Arg3.1-deficient mice and demonstrated learning and memory impairment in these mice in the Morris 
water maze task, contextual and cued fear conditioning, novel object recognition, and the conditioned taste-aversion test. These results indicate that Arc/Arg3.1 regulates a wide range of learning and memory function. According to both behavioral and electrophysiological data, they concluded that Arc/Arg3.1 is essential for LTM. Although the authors concluded that Arc/Arg3.1 does not play a significant role in synaptic potentiation and early LTP, they did not show adequate behavioral evidence to conclude the role of Arc/Arg3.1 in the fear memory (they only showed intact short-term memory (STM) 10 min after the initial trial, and intact novel object recognition test). LTM deficiency in Arc/Arg3.1deficient mice was evident about 120 min after highfrequency stimuli. Thus, the additional memory tests are necessary that should be conducted at about $120 \mathrm{~min}$ or later after the training and/or conditioning.

Arc/Arg3.1 may be involved in the endocytosis of AMPA-type glutamate receptors [3-5] by inducing the internalization of AMPA receptors. The morphological properties of AMPA receptors in Arc/Arg3.1-deficient mice were not, however, analyzed, and how AMPA receptor trafficking relates to impaired LTM remains unknown.

Ube3A regulates Arc/Arg3.1 degradation in synapses, and mutation of Ube3A may be a cause of autism spectrum disorders [26-28] and Angelman syndrome [29,30]. Using Ube3A-deficient mice, Greer et al. [31] recently reported that an increase in Arc/Arg3.1 expression leads to a decrease in the number of AMPA receptors. These results suggest that there may be abnormal expression of AMPA receptors in Arc/Arg3.1-deficient mice.

In order to elucidate the memory process of Arc /Arg3.1-deficient mice, in our current study, we used classical fear conditioning paradigm. First, we confirmed the LTM impairment in Arc/Arg3.1-deficient mice. Then, we conducted a time course analysis of the memory impairment of Arc/Arg3.1-deficient mice, and assessed the remote memory function of the mutant mice. Furthermore, we compared the brain structure between wildtype and Arc/Arg3.1-deficient mice by immunohistochemically.

\section{RESULTS}

\subsection{Successful Generation of Arc/Arg3.1-Deficient Mice}

We generated Arc/Arg3.1-deficient mice with MS12 ES cells derived from the C57BL/6 mouse strain (Supplemental information). Before conducting fear-conditioning experiments, we confirmed the intact pain sensation of Arc/Arg3.1-deficient mice with a tail-flick and a hotplate paradigm in another batch of mice ( $n=10$ each). In both tests, they displayed responses indistinguishable from those of wild-type littermates (data not shown). These results indicated that Arc/Arg3.1-deficient mice had normal pain sensation and that they and their wildtype littermates would respond equivalently to electric foot shocks. Therefore, a classical fear-conditioning paradigm was appropriate to assess their memory function.

\subsection{Arc/Arg3.1-Deficient Mice Exhibited Impairment in Both Contextual Fear and Cued Fear Memory}

Classical fear conditioning consists of a conditioning phase, a context test, and an auditory cued test. Arc/ Arg3.1-deficient mice exhibited a clearly lower occurrence of freezing than did wild-type mice in the context test. The mean percentage of freezing frequency was significantly lower in Arc/Arg3.1-deficient mice (MannWhitney's U-test, $\mathrm{U}=15, p<0.01$; Figure 1A). The subsequent auditory cue test consisted of two parts: the first half was done without a cue to assess the non-specific and/or generalized fear response to the new context, and the latter half was done with an auditory cue to assess the fear response to the cue (Figure 1B). The mean freezing frequency of Arc/Arg3.1-deficient mice was also significantly lower than that of wild-type mice under both conditions (without cue: Mann-Whitney's U-test, $\mathrm{U}=18, p<0.05$; with cue: $\mathrm{U}=$ $0, p<0.001)$. The identical tests were replicated five times with both male and female mice. There were no differences in impaired memory performance according to sex. Female Arc/Arg3.1-deficient mice did, however, display a significantly lower freezing frequency (data not shown). Arc/Arg3.1-deficient mice showed a significant decrease in the freezing response to the new context without an auditory cue. Because the results of the cued

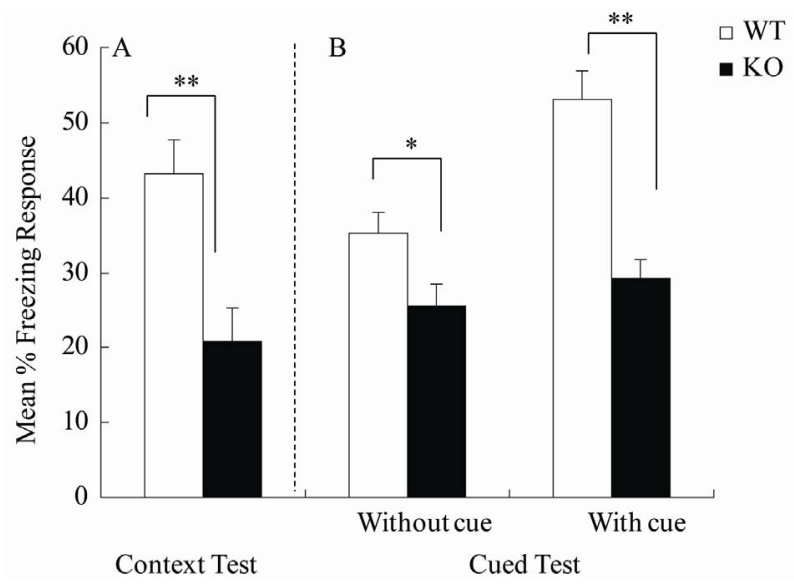

Figure 1. Summary of contextual and cued-fear memory performance of wild-type (WT) and Arc/Arg3.1-deficient (KO) mice. (A) Results of the context test. (B) Results of the cued test. Data represent the mean \pm S.E.M. Asterisks indicate statistical significance $\left(* *, \mathrm{p}<0.01{ }^{*}, \mathrm{p}<0.05\right)$. 
test reflect both generalized contextual fear [32] and cued fear, cued tests may be redundant. Therefore, only the contextual test trial was used in the following experiments.

\subsection{Arc/Arg3.1-Deficient Mice Exhibited Intact STM but Impaired LTM}

We conducted fear-conditioning tests to compare STM, LTM, and the retention of LTM in wild-type and Arc/ Arg3.1-deficient mice. In the initial context test $(4 \mathrm{hr}$ after conditioning), the mean percentage of freezing of Arc/Arg3.1-deficient mice was indistinguishable from that of wild-type mice (Mann-Whitney's U-test, $U=42$, n.s.; Figure 2). In the second context test conducted $24 \mathrm{hr}$ after conditioning, the mean percentage of freezing of Arc/Arg3.1-deficient mice was, however, significantly lower than that of wild-type mice (Mann-Whitney's U-test, $\mathrm{U}=24, \mathrm{p}<0.05$; Figure 2). In the 1-week and 4-week tests, the mean percentage of freezing of Arc/ Arg3.1-deficient mice was also significantly lower than that of wild-type mice (1-week test: Mann-Whitney's U-test, $\mathrm{U}=2$, $\mathrm{p}<0.01$; 4-week test: Mann-Whitney's U-test, $U=0, p<0.01$; Figure 2). The freezing frequency of wild-type mice increased significantly during the experiment, contrary to that of Arc/Arg3.1-deficient mice, whose freezing frequency decreased significantly (Two-way ANOVA with repeated measures: genotype, $\mathrm{F}(79,1)=58.5, \mathrm{p}<0.001$; retention time, $\mathrm{F}(79,3)=2.47$, $\mathrm{p}=0.07$, n.s.; genotype $\times$ retention time, $\mathrm{F}(79,3)=12.6$, $\mathrm{p}<0.001$; wild-type 4 hr vs. 4 week, $\mathrm{t}=3.33$, $\mathrm{p}<0.01$; Arc/Arg3.1-deficient mice 4 hr vs. 4 week, $\mathrm{t}=4.91$, $\mathrm{p}<$ $0.01)$.

\subsection{Arc/Arg3.1-Deficient Mice Showed Almost No Remote Memory of Fear}

As in the STM and LTM test, the same mice were used

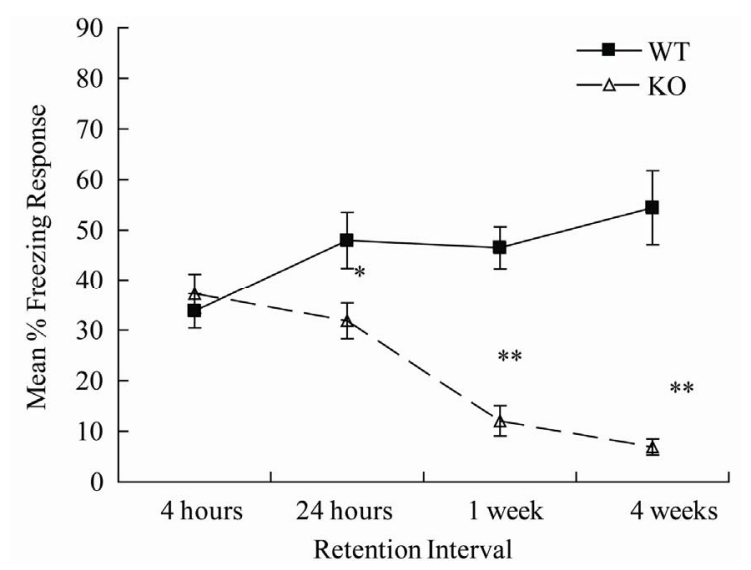

Figure 2. Summary of the STM and LTM tests of wild-type (WT) and Arc/Arg3.1-deficient (KO) mice. Data represent the mean \pm S.E.M. Asterisks indicate statistical significance $(* *, \mathrm{p}<0.01 ; *, \mathrm{p}<0.05)$. for all experiments, because the retention curve could have been affected by the repeated exposure to the conditioning context (e.g., reconsolidation, Suzuki et al., [33]). Therefore, we conducted a remote memory test. Mice were conditioned and kept without any treatment except standard daily care for 4 weeks, and then we conducted a context test. Wild-type mice showed a high freezing frequency, but Arc/Arg3.1-deficient mice did not show any freezing response (Mann-Whitney's U-test: $\mathrm{U}=0, \mathrm{p}<0.01$; Figure 3).

\subsection{AMPA Receptors Were Expressed at Higher Levels in the Hippocampus of Arc/Arg3.1-Deficient Mice}

Immunohistochemical analyses were conducted to clarify the distribution of neuronal processes and synapses. Although increased immunoreactivity for neuronal processes (NF-M, MAP1A) was detected in the cerebral cortex of Arc/Arg3.1-deficient mice, no substantial differences were detected in the hippocampal region (Figure 4). Nevertheless, immunoreactivity for pre- and post-synaptic proteins (SYP, HOM) was somewhat increased in the hippocampus of Arc/Arg3.1-deficient mice (Figure 4). We also found increased immunoreactivity for GluR1 in the CA1 region and dentate gyrus (DG) of the hippocampus and for SYP in the CA3 region of Arc/Arg3.1- deficient mice as compared with that of wild-type mice (Figure 5). In order to confirm the in creased GluR1 reactivity in hippocampus, we calculated the ratio of fluorescence intensity and compared between wild-type and Arc/Arg3.1-deficient mice in a semi- quantitative manner. Arc/Arg3.1-deficient mice exhibited

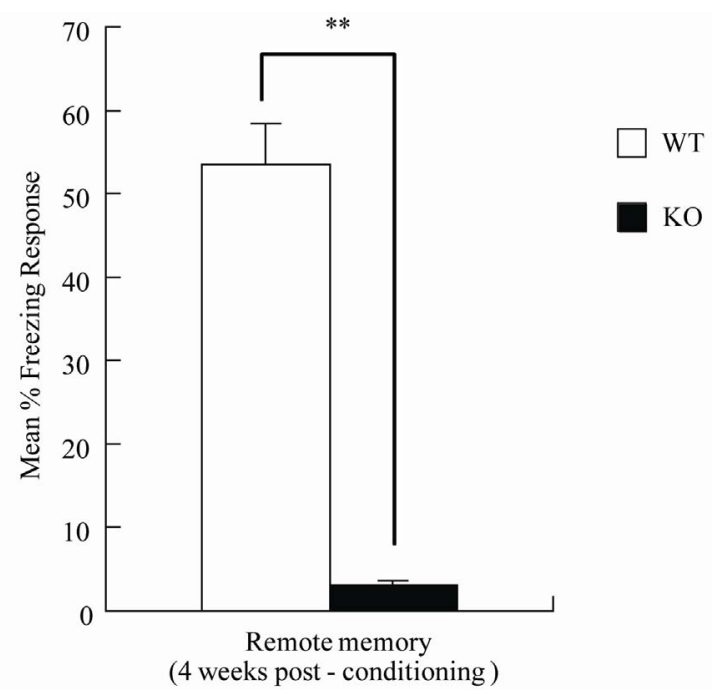

Figure 3. Summary of remote memory test of wildtype (WT) and Arc/Arg3.1-deficient (KO) mice. Data represent the mean \pm S.E.M. Asterisks indicate statistical significance $(* *, \mathrm{p}<0.01)$. 
WT
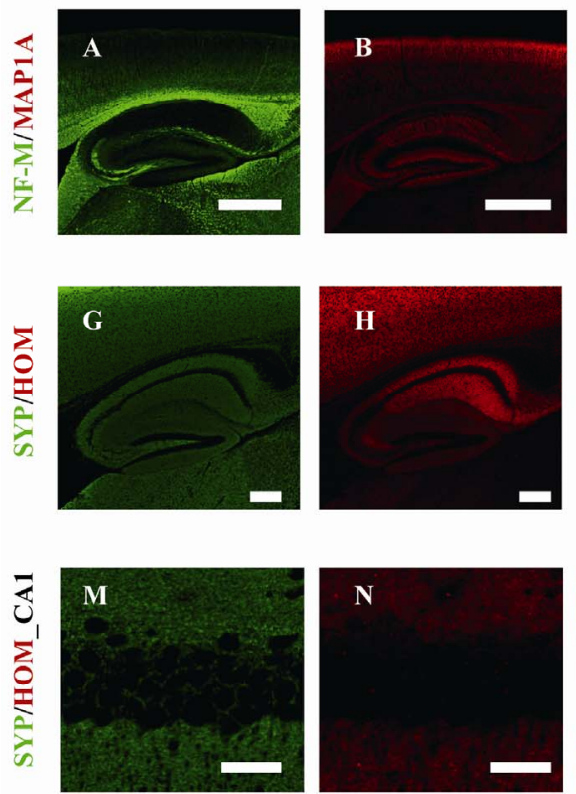

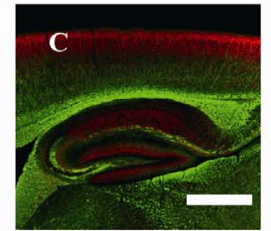

Bar $=500$ um

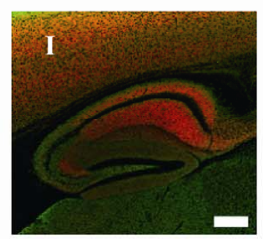

Bar $=200 \mathrm{um}$

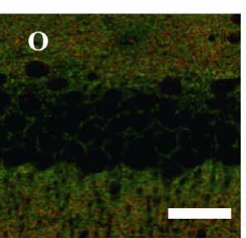

Bar $=20$ um
KO
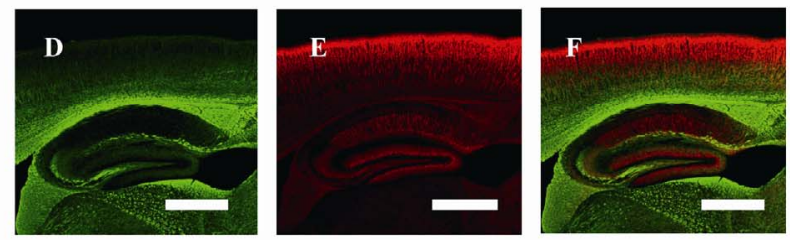

Bar $=500 \mathrm{um}$
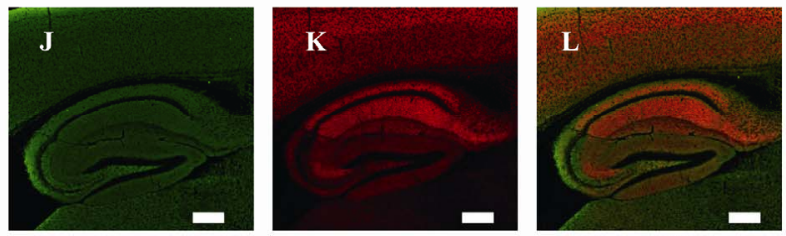

$\operatorname{Bar}=200 \mathrm{um}$
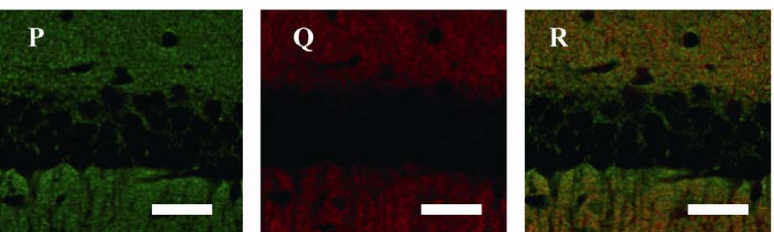

Bar $=20$ um

Figure 4. Immunohistochemical analysis of hippocampal neurons and synapses of wild-type (WT) and Arc/Arg3.1-deficient (KO) mice. A-F, Immunohistochemical images of neurofilament-m (NF-M; green) and MAP1A (red). G-R, Immunohistochemical images of synaptophysin (SYP; green) and homer (HOM; red). A-C, G-I, and M-O, wild-type mice. D-F, J-L, and P-R, Arc/Arg3.1-deficient (KO) mice. C, F, I, L, O, and R, merged images. A-F, cerebral cortex and hippocampus; scale bar $=500 \mu \mathrm{m}$. $\mathrm{G}-\mathrm{L}$, hippocampus; scale bar $=200 \mu \mathrm{m}$. M-R, CA1 region of the hippocampus; scale bar $=20 \mu \mathrm{m}$.

WT
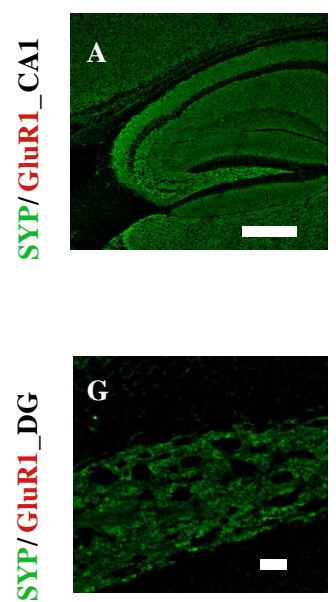
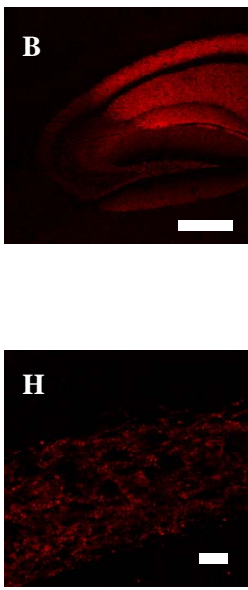

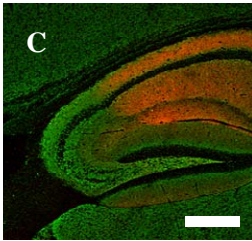

Bar $=200 \mathrm{um}$

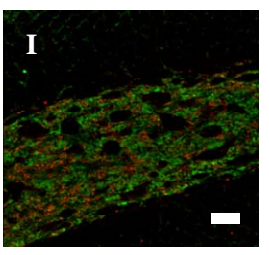

Bar $=20$ um
KO
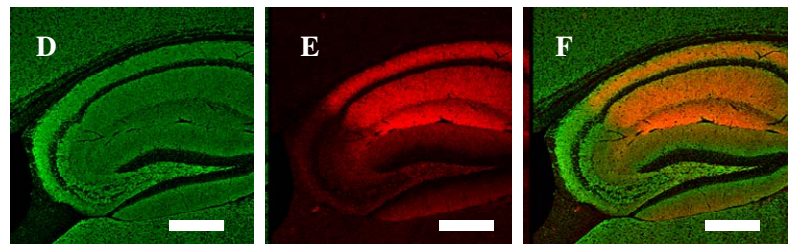

Bar $=200 \mathrm{um}$
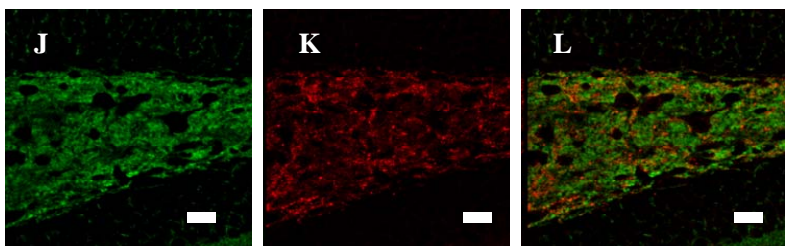

Bar $=20$ um

Figure 5. Immunohistochemical analysis of the distribution of AMPA-type glutamate receptors (GluR1) in wild-type and Arc/Arg3.1-deficient (KO) mice. Immunohistochemical images of synaptophysin (SYP, green) and AMPA-type glutamate receptors (GluR1, red). A-C and G-I, wild-type mice. D-F and J-L, Arc/Arg3.1-deficient (KO) mice. C, F, I, and L, merged images. Scale bars are identical as those of Figure 4.

statistically significant increase of GluR1 immunoreactivity in CA1 and CA3 (both $\mathrm{p}<0.01$, Figure 6).

\section{DISCUSSION}

In our current study, we demonstrated impaired fear memory in Arc/Arg3.1-deficient mice. In addition, immunohistochemical analysis revealed changes in synaptic structure and increased AMPA receptor expression in the hippocampus of Arc/Arg3.1-deficient mice. These findings suggest that Arc/Arg3.1 plays crucial roles not 


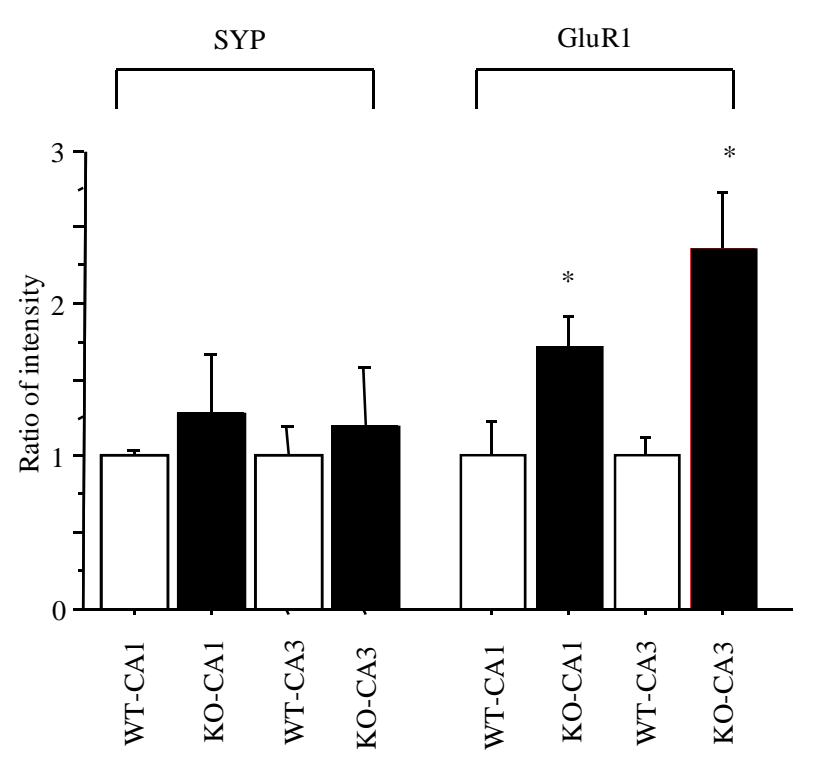

Figure 6. Ratio of fluorescence intensity. SYP: synaptophysin, GluR1: AMPA-type glutamate receptors, WT: wild-type mice, KO: Arc/Arg3.1-deficient mice. Data represent mean + SEM. *: $\mathrm{p}<0.01$ (compared to wild-type mice).

only in LTM formation but also in the memory retention process. Although an AMPA potentiator did not lead to recovery of the impaired memory in Arc/Arg3.1-deficient mice (Supplemental information and Supplemental Figure 2), this is the first study that used Arc/Arg3.1deficient mice to assess the effect of drugs on memory impairment.

Arc/Arg3.1-deficient mice exhibited a lower percentage of freezing than did wild-type mice in the context and cued-memory test, indicating that Arc/Arg3.1-deficient mice were impaired in both contextual and cued memory. Many studies have reported that contextual fear reflects hippocampus-dependent memory function, and cued fear reflects amygdala-dependent memory function (for review, see LeDoux, [34]). Therefore, Arc/Arg3.1deficient mice may be impaired in both hippocampusand amygdala-dependent memory function. These results suggest that Arc/Arg3.1 may function in the amygdala for auditory fear memory formation as well as in the hippocampus for spatial memory formation. Arc/Arg3.1deficient mice did, however, show a significant decrease in the freezing response to the new context without an auditory cue in the cued test. This result indicates that the freezing response in the cued test may reflect both generalized contextual fear and cued fear. Therefore, new experimental tasks or protocols should be developed to clarify the role of Arc/Arg3.1 in amygdala-dependent memory processes.

In this study, we examined STM and LTM in Arc/ Arg3.1-deficient mice. Arc/Arg3.1-deficient mice exhib- ited unimpaired memory performance $4 \mathrm{hr}$ after conditioning, indicating that their STM or early stage of LTM was intact. In contrast, $24 \mathrm{hr}$ after the conditioning trial, the memory performance of Arc/Arg3.1-deficient mice was greatly impaired. After 4 weeks, their memory was almost completely absent, whereas that of wild-type mice slightly but significantly increased. This differential retention process may be partly due to repeated exposure to the conditioning context. Short exposure to conditioned stimuli may enhance fear memory (reconsolidation: [33,35]). Decreased fear memory by repeated exposure indicates that the reconsolidation process may also be impaired in Arc/Arg3.1-deficient mice. Thus, we assessed remote memory (ability to retrieve distant episodes/events) directly and confirmed complete impairment of remote memory in Arc/Arg3.1-deficient mice.

Immunohistochemical analyses revealed increased expression of AMPA-type glutamate receptors in hippocampal regions. This result is consistent with previous studies reporting that Arc/Arg3.1 may be involved in endocytosis of AMPA-type glutamate receptors and may prompt the internalization of AMPA receptors [3-5]. Although LTP, especially early-phase LTP, depends on NMDA receptors ([36] for review), activation of AMPA receptors may improve memory function in rats and mice $[37,38]$. Therefore, this mutant mouse strain will be useful for developing treatments including drugs for memory impairment.

\section{EXPERIMENTAL PROCEDURES}

\subsection{The Behavioral Laboratory Environment and Housing Conditions of Mice}

Mice were housed individually before transfer to the behavioral laboratory. They were kept in the laboratory during the behavioral analysis under a light/dark cycle of $12 \mathrm{hr} / 12 \mathrm{hr}$ (lights on at 8:00). The laboratory was air conditioned, and the temperature and humidity were maintained at $\sim 22^{\circ} \mathrm{C}-23^{\circ} \mathrm{C}$ and $50 \%-55 \%$, respectively. Food and water were freely available except during experimentation unless otherwise indicated. We used large tweezers with soft vinyl tips to handle the mice to avoid potential differences in the handling technique of the different researchers involved in the study.

Animal experiments in this study were conducted in strict accordance with the guidelines of the Institute of Physical and Chemical Research (RIKEN) and were approved by the Animal Investigation Committee of the Institute.

\subsection{Classical Fear Conditioning}

\subsubsection{Contextual and Cued Test}

Twenty mice (wild type, $\mathrm{n}=10$; Arc/Arg3.1 deficient, $\mathrm{n}$ $=10$; 9 weeks of age) were used. This test consisted of 
three parts: a conditioning trial, a context test trial, and a cued test trial. Fear conditioning was carried out on a clear plastic chamber equipped with a stainless-steel grid floor $(34 \times 26 \times 30[\mathrm{H}] \mathrm{cm})$. The luminance of the floor was 225 Lux in the conditioning and context test trial and $0-1$ Lux in the cued test trial. A CCD camera was installed on the ceiling of the chamber and was connected to a video monitor and a Windows PC. The grid floor was wired to a shock generator. White noise ( $65 \mathrm{~dB}$ ) was supplied from a loudspeaker as an auditory cue (conditioned stimulus, CS). The conditioning trial consisted of a 2-min exploration period followed by two CS-unconditioned stimulus (US) pairings separated by 1 min each. A US (foot-shock: $0.5 \mathrm{~mA}, 2 \mathrm{sec}$ ) was administered at the end of the 30 -sec CS period. A context test was performed in the same conditioning chamber for 3 min in the absence of the white noise $24 \mathrm{hr}$ after the conditioning trial. In addition, a cued test was performed in an alternative context with distinct cues: the test chamber was different from the conditioning chamber in brightness (dark environment, almost 0-1 Lux), color (white), floor structure (no grid), and shape (triangular). The cued test was conducted $24 \mathrm{hr}$ after the contextual test was finished, and consisted of a 2-min exploration period (no CS) to evaluate the nonspecific contextual fear followed by a 2-min CS period (no foot shock) to evaluate the acquired cued fear.

\subsubsection{STM and LTM Test}

A second set of mice (wild type, $\mathrm{n}=10$; $\operatorname{Arc} / \operatorname{Arg} 3.1$ deficient, $n=10$; 9 weeks of age) was used for these tests. The conditioning trial was the same as in the above contextual and cued test (see 4.2.1). After $4 \mathrm{hr}$, an STM test was conducted, and LTM tests were conducted $24 \mathrm{hr}, 1$ week, and 4 weeks later. STM and LTM tests were the same as the context test of 4.2.1. In this test, the cued test was not conducted to exclude any sensitization effect caused by the auditory cue.

\subsubsection{Remote Memory Test}

A third set of mice (wild type, $\mathrm{n}=10$; Arc/Arg3.1 deficient, $\mathrm{n}=10$; 9 weeks of age) was used. The conditioning trial was the same as in the above STM and LTM test (see 4.2.2). In this test, a context test was conducted 4 weeks after the conditioning trial.

Both the contextual and cued tests and the STM and LTM tests were replicated five times to confirm their reproducibility. The rate of the freezing response (immobility excluding respiration and heartbeat) of mice was measured as an index of fear memory. Data were collected and analyzed with Image J FZ2 (O’Hara, Tokyo, Japan; Image J XX is modified software based on the public domain Image J program developed at the U.S. National Institutes of Health and is available at http://rsb.info.nih.gov/ij).

\subsection{Immunohistochemical Analysis}

Brains ( $\mathrm{n}=4$ male mice per group) were fixed with methacarn fixative (methanol/chloroform/acetic acid, 60:30: $10[\mathrm{v} / \mathrm{v}]$ ), and paraffin-embedded sections were prepared [39]. Mouse monoclonal anti-neurofilament (NF-M, sc-20013; Santa Cruz Biotechnology, CA, USA; 1:1000; a marker for axons), rabbit polyclonal anti- microtubule-associated protein 1A (MAP1A, sc-25728; Santa Cruz Biotechnology; 1:1000; a marker for dendrites), mouse monoclonal anti-synaptophysin (SYP, sc-17750; Santa Cruz Biotechnology; 1:1000; a pre- synaptic marker), rabbit polyclonal anti-homer (HOM, sc-15321; Santa Cruz Biotechnology; 1:500; a post- synaptic marker), and anti-GluR1(GluR1, sc-28779; Santa Cruz Biotechnology; 1:500) were used for immunohistochemistry. Sections were pretreated with HistoVT-One (Na- calai Tesque, Japan) and incubated with primary antibodies. Signals were visualized with Alexa 568-conjugated anti-mouse IgG and Alexa 488-conjugated anti-rabbit IgG (Molecular Probes, OR). Images were obtained with an FV-300 confocal laser-scanning microscope (Olympus, Japan).

For semi-quantitative analysis of image, the ratio of fluorescence intensity was calculated and compared Arc/Arg3.1-deficient mice to wild-type by using IMAGE J program (http://rsb.info.nih.gov/ij/index.html. National Institute of Health, Bethesda), after adjusting background noise ( $\mathrm{n}=4$ images per mouse).

\section{ACKNOWLEDGEMENTS}

We thank Dr. Yoshitake Sano for his comments and suggestions regarding this study. We also thank Dr. Mariko Katayama for her assistance in maintaining the Arc/Arg3.1-deficient mouse line.

\section{REFERENCES}

[1] Guzowski, J., Lyford, G., Stevenson, G., et al. (2000) Inhibition of activity-dependent arc protein expression in the rat hippocampus impairs the maintenance of long-term potentiation and the consolidation of long-term memory. The Journal of Neuroscience, 20, 3993-4001.

[2] Plath, N., Ohana, O., Dammermann, B., et al. (2006) Arc/ Arg3.1 is essential for the consolidation of synaptic plasticity and memories. Neuron, 52, 437-444. doi:10.1016/j.neuron.2006.08.024

[3] Chowdhury, S., Shepherd, J.D., Okuno, H., et al. (2006) Arc/Arg3.1 interacts with the endocytic machinery to regulate AMPA receptor trafficking. Neuron, 52, 445- 459. doi:10.1016/j.neuron.2006.08.033

[4] Rial Verde, E.M., Lee-Osbourne, J., Worley, P.F., et al. (2006) Increased expression of the immediate-early gene Arc/Arg3.1 reduces AMPA receptor-mediated synaptic transmission. Neuron, 52, 461-474. 
doi:10.1016/i.neuron.2006.09.031

[5] Shepherd, J.D., Rumbaugh, G., Wu, J., Chowdhury, S., et al. (2006) Arc/Arg3.1 mediates homeostatic synaptic scaling of AMPA receptors. Neuron, 52, 475-484. doi:10.1016/j.neuron.2006.08.034

[6] Steward, O. and Worley, P. (2002) Local synthesis of proteins at synaptic sites on dendrites: role in synaptic plasticity and memory consolidation? Neurobiology of Learning and Memory, 78, 508-527. doi:10.1006/nlme.2002.4102

[7] Lyford, G., Yamagata, K., Kaufmann, W., et al. (1995) Arc, a growth factor and activity-regulated gene, encodes a novel cytoskeleton-associated protein that is enriched in neuronal dendrites. Neuron, 14, 433-445. doi:10.1016/0896-6273(95)90299-6

[8] Rodríguez, J.J., Davies, H.A., Silva, A.T., et al. (2005) Long-term potentiation in the rat dentate gyrus is associated with enhanced Arc/Arg3.1 protein expression in spines, dendrites and glia. European Journal of Neuroscience, 21, 2384-2396. doi:10.1111/j.1460-9568.2005.04068.x

[9] Steward, O. and Worley, P. (2001) A cellular mechanism for targeting newly synthesized mRNAs to synaptic sites on dendrites. Proceedings of the National Academy of Sciences of the United States of America, 98, 7062-7068. doi:10.1073/pnas.131146398

[10] Fosnaugh, J., Bhat, R., Yamagata, K., et al. (1995) Activation of arc, a putative "effector" immediate early gene, by cocaine in rat brain. Journal of Neurochemistry, 64, 2377-2380. doi:10.1046/j.1471-4159.1995.64052377.x

[11] Kodama, M., Akiyama, K., Ujike, H., et al. (1998) A robust increase in expression of arc gene, an effector immediate early gene, in the rat brain after acute and chronic methamphetamine administration. Brain Research, 796, 273-283.

doi:10.1016/S0006-8993(98)00349-7

[12] Moro, H., Sato, H., Ida, I., et al. (2007) Effects of SKF-38393, a dopamine D1 receptor agonist on expression of amphetamine-induced behavioral sensitization and expression of immediate early gene arc in prefrontal cortex of rats. Pharmacology Biochemistry and Behavior, 87, 56-64. doi:10.1016/j.pbb.2007.03.020

[13] Yamagata, K., Suzuki, K., Sugiura, H., et al. (2000) Activation of an effector immediate-early gene arc by methamphetamine. Annals of the New York Academy of Sciences, 914, 22-32.

doi:10.1111/j.1749-6632.2000.tb05180.x

[14] Nakahara, T., Kuroki, T., Hashimoto, K., et al. (2000) Effect of atypical antipsychotics on phencyclidine-in- duced expression of arc in rat brain. NeuroReport, 11, 551-555. doi:10.1097/00001756-200002280-00025

[15] Kremerskothen, J., Wendholt, D., Teber, I., et al. (2002) Insulin-inducedexpression of the activity-regulated cytoskeleton-associated gene (ARC) in human neuroblastoma cells requires p21(ras), mitogen-activated protein kinase/ extracellular regulated kinase and src tyrosine kinases but is protein kinase C-independent. Neuroscience Letters, 22 , 153-156.

[16] Kunizuka, H., Kinouchi, H., Arai, S., et al. (1999) Activation of arc gene, a dendritic immediate early gene, by middle cerebral artery occlusion in rat brain. NeuroReport, 10, 1717-1722.

\section{doi:10.1097/00001756-199906030-00017}

[17] Larsen, M.H., Olesen, M., Woldbye, D.P., et al. (2005) Regulation of activity-regulated cytoskeleton protein (arc) mRNA after acute and chronic electroconvulsive stimulation in the rat. Brain Research, 1064, 161-165. doi:10.1016/j.brainres.2005.09.039

[18] Mikkelsen, J.D. and Larsen, M.H. (2006) Effects of stress and adrenalectomy on activity-regulated cytoskeleton protein (arc) gene expression. Neuroscience Letters, 403, 239-243. doi:10.1016/j.neulet.2006.04.040

[19] Guthrie, K., Rayhanabad, J., Kuhl, D., et al. (2000) Odors regulate Arc expression in neuronal ensembles engaged in odor processing. NeuroReport, 11, 1809-1813. doi:10.1097/00001756-200006260-00003

[20] Matsuoka, M., Yamagata, K., Sugiura, H., et al. (2002) Expression and regulation of the immediate-early gene product Arc in the accessory olfactory bulb after mating in male rat. Neuroscience, 11, 251-258.

[21] Montag-Sallaz, M. and Montag, D. (2003) Learninginduced arg 3.1/arc mRNA expression in the mouse brain. Learning and Memory, 10, 99-107. doi:10.1101/lm.53403

[22] Kelly, M.P. and Deadwyler, S.A. (2003) Experiencedependent regulation of the immediate-early gene arc differs across brain regions. The Journal of Neuroscience, 23, 6443-6451.

[23] Taishi, P., Sanchez, C., Wang, Y., et al. (2001) Conditions that affect sleep alter the expression of molecules associated with synaptic plasticity. American Journal of Physiology: Regulatory Integrative and Comparative Physiology, 281, R839-R845.

[24] Kelly, M.P. and Deadwyler, S.A. (2002) Acquisition of a novel behavior induces higher levels of arc mRNA than does overtrained performance. Neuroscience, 110, 617626. doi:10.1016/S0306-4522(01)00605-4

[25] Ons, S., Martí, O. and Armario, A. (2004) Stress-induced activation of the immediate early gene Arc (activity-regulated cytoskeleton-associated protein) is restricted to telencephalic areas in the rat brain: relationship to c-fos mRNA. Journal of Neurochemistry, 89, 1111-1118. doi:10.1111/j.1471-4159.2004.02396.x

[26] Cook, E.H., Jr., Lindgren, V., Leventhal, B.L., et al. (1997) Autism or atypical autism in maternally but not paternally derived proximal $15 q$ duplication. The American Journal of Human Genetics, 60, 928-934.

[27] Glessner, J.T., Wang, K., Cai, G., Korvatsuka, O., et al. (2009) Autism genome-wide copy number variation reveals ubiquitin and neuronal genes. Nature, 459, 569573. doi:10.1038/nature07953

[28] Suteliffe, J.S., Nurmi, E.L. and Lombroso, P.J. (2003) Genetics of childhood disorders: XLVII. Autism, part 6: duplication and inherited susceptibility of chromosome 15q11-q13 genes in autism. Journal of the American Academy of Child and Adolescent Psychiatry, 42, 253-256. doi:10.1097/00004583-200302000-00021

[29] Kishino, T., Lalande, M. and Wagstaff, J. (1997) UBE3A/ E6-AP mutations cause Angeleman syndrome. Nature Genetics, 15, 70-73. doi:10.1038/ng0197-70

[30] Matsuura, T., Sutcliffe, J. S., Fang, P., et al. (1997) De novo truncating mutations in E6-AP ubiquitin-protein ligase gene (UBE3A) in Angelman syndrome. Nature Genetics, 15, 74-77. doi:10.1038/ng0197-74 
[31] Greer, P.L., Hanayama, R., Bloodgood, B.L., et al. (2010) The Angelman Syndrome protein Ube3A regulates synapse development by ubiquitinating arc. Cell, 140, 704716. doi:10.1016/j.cell.2010.01.026

[32] Radulovic, J., Kammermeir, J. and Spiess, J. (1998) Generalization of fear responses in C57BL/6J mice subjected to one-trial foreground contextual fear conditioning. Behavioral Brain Research, 95, 179-189. doi:10.1016/S0166-4328(98)00039-4

[33] Suzuki, A., Josselyn, S.A., Frankland, P.W., et al. (2004) Memory reconsolidation and extinction have distinct temporal and biochemical signatures. The Journal of Neuroscience, 24, 4787-4795.

doi:10.1523/JNEUROSCI.5491-03.2004

[34] LeDoux, J. (1993) Emotional memory: in search of systems and synapses. Annals of the New York Academy of Sciences, 702, 149-157. doi:10.1111/j.1749-6632.1993.tb17246.x

[35] von Hertzen, L.S.J. and Giese, K.P. (2005) Memory reconsolidation engages only a subset of immediate-early genes induced during consolidation. The Journal of Neuroscience, 25, 1935-1942.

\section{Abbreviations}

Arc/Arg3.1: activity-regulated cytoskeleton-associated protein; LTP: long-term potentiation; LTM: long-term memory; STM: short-term memory; NF-M: neuro-
[36] MacDonald, J.F., Jackson, M.F. and Beazely, M.A. (2006) Hippocampal long-term synaptic plasticity and signal amplification of NMDA receptors. Critical Reviews in Neurobiology, 18, 71-84.

[37] Sekiguchi, M., Yamada, K., Jin, J., et al. (2001) The AMPA receptor allosteric potentiator, PEPA ameliorates post-ischemic memory impairment. NeuroReport, 12, 29472950. doi:10.1097/00001756-200109170-00038

[38] Yamada, D., Zushida, K., Wada, K., et al. (2009) Pharmacological discrimination of extinction and reconsolidation of contextual fear memory by a potentiator of AMPA receptors. Neuropsychopharmacology, 34, 25742584. doi:10.1038/npp.2009.86

[39] Tanemura, K., Igarashi, K., Matsugami, T.-R., et al. (2009) Intraurine environment-genome interaction and children's development (2): EBrain structure impairment and behavioral disturbance induced in male mice offspring by a single intraperitoneal administration of domoic acid (DA) to their dams. The Journal of Toxicological Sciences, 34, 279-286. doi:10.2131/jts.34.SP279

filament-M; MAP1A: microtubule-associated protein 1A; SYP: synaptophysin; HOM: homer; DG: dentate gyrus. 